\title{
Microplastics in Swiss floodplain soils
}

Michael Scheurer and Moritz Bigalke*

Institute of Geography, University of Bern, Hallerstrasse 12, 3012 Berne, Switzerland

*Corresponding author: Moritz Bigalke, moritz.bigalke@giub.unibe.ch, tel. +41(0)316314055

\begin{abstract}
Microplastics (MPs) are small ( $<5 \mathrm{~mm}$ diameter) but have clear implications for the environment. These artificial particles are found in and pose threats to aquatic systems worldwide. MPs have terrestrial sources, but their concentrations and fates in the terrestrial environment are poorly understood. Whilst global plastic production continues to increase, so do the environmental concentrations and impacts of MPs. In this first study of MPs in floodplain soils, we developed a method for identifying, quantifying, and measuring the sizes of most commonly produced MPs in soil by FT-IR microscopy. For small MP $(<1 \mathrm{~mm})$ analysis, MP were separated by density separation and oxidation of organic matter. In this study we analyzed 29 floodplains in Swiss nature reserves associated with catchments covering 53\% of Switzerland. We found evidence that $90 \%$ of Swiss floodplain soils contain MPs. The highest MP concentrations were associated with the concentration of mesoplastics (5 mm $-2.5 \mathrm{~cm}$ diameter), indicating plastic waste as source. Furthermore, MP concentration was correlated with the population of the catchment. The wide distribution of MPs, their presence in remote unsettled high mountain areas, decoupling of MEP and MP compositions, and the dominance of MPs by small ( $<500 \mu \mathrm{m}$ diameter) particles, indicate that MPs enter soils via diffuse aeolian transport.
\end{abstract}

\section{TOC ART}

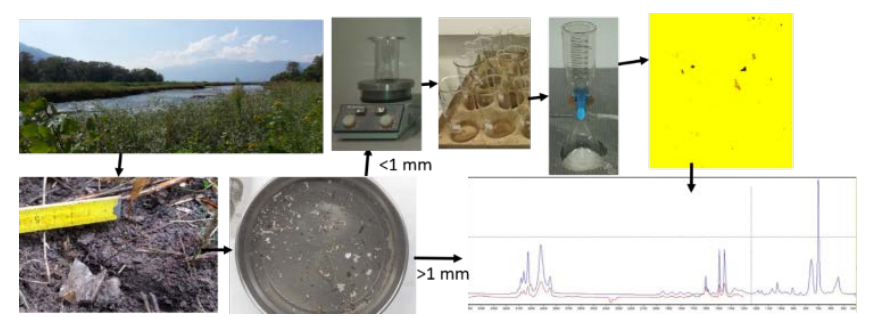




\section{Introduction}

Microplastics (MPs) in the environment are of great concern, ${ }^{1}$ mostly because of their ubiquity and their negative effects on marine ecosystems. ${ }^{2}$ MPs are commonly subdivided into small $(<1 \mathrm{~mm}$ diameter $)$ and large (1-5 mm diameter) MPs and are classed separately from mesoplastics (MEPs; $5 \mathrm{~mm}-2.5 \mathrm{~cm}$ diameter). ${ }^{3}$ The highest demanded plastics in Europe are polypropylene (PP), polyethylene (PE), polyvinyl chloride (PVC), polyurethane (PUR), polyethylene terephthalate (PET), polystyrene (PS), acrylonitrile butadiene styrene (ABS), styrene-acrylonitrile copolymer (SAN), styrene butadiene (SBR), polyamide (PA), polycarbonate (PC), polymethyl methacrylate (PMMA). ${ }^{4}$

MPs are inherently toxic to aquatic organisms ${ }^{2,5,6}$ and can act as carriers for a wide range of pollutants. ${ }^{7}$ ${ }^{8}$ MPs may also pose risks to human health. ${ }^{1}$ Their sources are mainly terrestrial, but their concentrations and fates in terrestrial environments remain poorly understood. ${ }^{9-11}$ In terrestrial ecosystems, soils are probably the major sinks for MPs. It has been estimated that the application of sewage sludge to arable land alone could add an annual MP load to soil greater than that entering the world's oceans. ${ }^{12}$ Applying sewage sludge to soil adds synthetic fibres, which have been found to be persistent and mobile. ${ }^{13}$ However, also after sewage sludge application has been banned in many countries, the application of compost and the use of plastic foil in agriculture can be significant sources. ${ }^{14,}{ }^{15}$ Industrial plastics, littering, road dust and diffuse atmospheric deposition, sedimentation from water flooding the soils or irrigation are other important sources of MPs in the environment. ${ }^{14} \mathrm{MP}$ concentrations up to $67,500 \mathrm{mg}$ $\mathrm{kg}^{-1}$ have recently been found at an industrial site in Australia. ${ }^{16}$

Earthworms are negatively affected by $\mathrm{MPs}^{17,18}$ at concentrations already found in soils. ${ }^{16}$ Indeed, histopathological and molecular effects of MP were already found at concentrations as low as 62.5-1000 $\mathrm{mg} \mathrm{kg}{ }^{-1} \cdot{ }^{19}$ Environmental MP concentrations in soils are therefore likely to affect soil organisms and decrease soil fertility, and thus alter soil ecological functioning and global food production. Even if the direct uptake of MPs by crops and the transfer of MPs to edible plant parts seems unlikely, MPs could enter the human food chain by other means. For example, MPs in soil could adhere to the surfaces of salad and root vegetables, as shown for numerous other pollutants. ${ }^{20,21}$ Also livestock like chicken may take up MP from the soil and may transfer it to the human food chain. ${ }^{22}$ Exposed agricultural soil 
surfaces could be important sources of MPs to the atmosphere or rivers (in runoff), and MPs in floodplains probably enter aquatic systems after being remobilized during heavy rain and flooding. ${ }^{1}$ Initial investigations have shown that MPs can be transported in soil. ${ }^{10,13,14,23,24}$ The general mobility in soils depends mainly on the size of the plastic and the texture of the soil. ${ }^{14}$ In fine grained homogeneous soils, the transport is probably not significant. ${ }^{25}$ However, transport might occure because of agricultural practices like ploughing, crack formation in soils, ${ }^{14}$ bioturbation ${ }^{10,23,} 24$ or through preferential flow. ${ }^{13}$ Thus, even if the transfer to groundwater is unlikely in most soils, ${ }^{14}$ in areas with high groundwater table and coarse soils, these transfer may occur.

The negative effects of MP on earthworms ${ }^{18,19,23}$ and the serious effects of MPs in marine systems ${ }^{2,5,6}$ are critical examples of their environmental effects, and indicate the need for both a precautionary approach and urgent action. Global plastic production is continually increasing, and $322 \times 10^{6} \mathrm{t}$ of plastics were produced in $2015,{ }^{4}$ so the impacts of MPs on the environment are thought to increase with its concentrations. ${ }^{1}$

One reason so few studies of MPs in terrestrial systems have been performed is that a suitable analytical method for the full characterization of MPs in soils is missing. There are two promising methods for MP characterization in soils published recently, however they are still limited in their potential to offer size information ${ }^{16}$ or are limited to light density plastics. ${ }^{26}$ So, to get more information about the fate of MPs in soils we aimed to a) develop a method to analyze size distribution, composition and concentrations of MPs in soils, b) analyze and characterize MPs in Swiss floodplain soils to assess its distribution and possible implication and c) to assess the sources and pathways of MPs in this Swiss floodplain soils.

This is the first study to provide a characterization of MPs in floodplain soils. It is also the first in which a convenient spatial basis has been used, achieved by analysing floodplain soils from a representative part of an entire country. Despite being a small country, the topography of Switzerland makes it very diverse in terms of climate and population density.

\section{Material \& Methods}

Study sites 
A number of criteria were set for use in the site selection process to allow the effects of the numbers of permanent inhabitants of the catchments and the textures of the floodplain soils on the MP concentrations to be investigated. First, the study sites were equally distributed according to the Strahler numbers (branching complexity) of the streams (Strahler numbers 1-8). We assumed the Strahler number to be an appropriate indicator of the populations of the drainage basins and the grain size distributions of the floodplain soils. Second, all the study sites were in wetlands of national importance and protected nature reserves. Third, study sites connected to each other by rivers were avoided to ensure the independence of each study site, for later statistical analysis. We used these criteria to select 29 study sites from an open-source georeferenced dataset for Swiss floodplain soils. ${ }^{27}$ Each sample was collected from a section of the river of interest with no indication of direct anthropogenic pollution. Each sample was collected from a floodplain at a straight part of the river, from $0.5-1 \mathrm{~m}$ higher in altitude than the visible maximum water level of the river. Three mixed samples were collected at each site, each mixed sample being composed of five subsamples collected $4 \mathrm{~m}$ apart from each other along a straight line in the floodplain parallel to the river edge (Figure 1). The first of the three mixed samples was collected approx. 3m away from the visible maximal extension of the river, the second sample was collected each $1 \mathrm{~m}$ closer to the river and $1 \mathrm{~m}$ upstream, and the third sample was collected another $1 \mathrm{~m}$ closer to the river and $1 \mathrm{~m}$ upstream. The different distances of the samples from the river had no significant effect on MP or MEP concentrations ( $\mathrm{p}=0.66$ ). Each soil sample was $8 \mathrm{~cm}$ wide, $8 \mathrm{~cm}$ long, and $5 \mathrm{~cm}$ deep. The soil samples were collected using steel tools, and each sample was packed into an aluminum box before being transported to the laboratory.

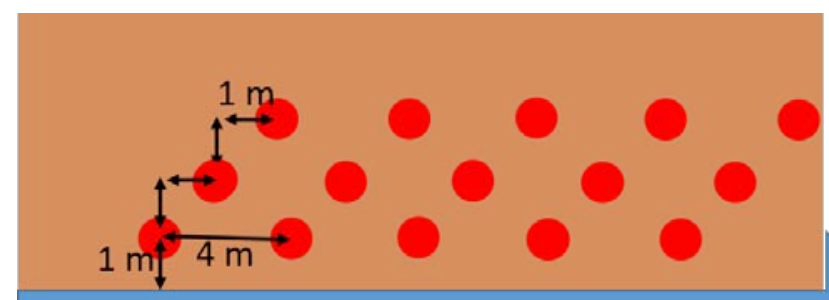

Mixed Sample I

Mixed Sample II

Mixed Sample III

\section{River}

Figure 1 Schematic of the sampling plan 
Development of the microplastic characterization method

The MPs in a soil sample were separated from the mineral fraction by density. We performed tests using $\mathrm{NaCl}\left(1,2 \mathrm{~g} \mathrm{~cm}^{-3}\right)$ and $\mathrm{CaCl}_{2}\left(1,5 \mathrm{~g} \mathrm{~cm}^{-3}\right)$ solutions. Four methods of separating the mineral particles from the supernatant were tested. The first was similar to the sedimentation cylinder method used by Schwarz, ${ }^{28}$ but our cylinder was a metal pipe with a ball valve in the middle to prevent the mineral particles and supernatant remixing. The cylinder was let stand for $48 \mathrm{~h}$ to allow for density separation by gravity. The second method involved a self-constructed MP separator (Figure S1). In this separator the sample was stirred in a density solution to allow separation of mineral and plastic particles. The separator allowed adding additional air bubbling to improve the separation, and automatic filling of the sample bottle. The separation of the MP was done by sucking the uppermost part of the density solution, which contains the MP particles, in a separate vial. The third method involved stirring the mixture for 10 minutes and afterwards separating the mineral from the plastic particles by centrifuging the mixture for 30 min at $3450 \mathrm{G}$. The fourth method was identical with the third one but with a rubber disc (Figure S2) inserted after centrifugation to prevent the mineral particles being resuspended. Each method was tested using $50 \mathrm{~g}$ of pure plastic-free sand spiked with 10 polypropylene MP particles $0.5-1 \mathrm{~mm}$ in diameter. Three or four replicates were tested using each method, and the recoveries were calculated by counting the particles after the separation process had been performed.

The density separation method could not separate MPs from all of the organic particles released from organic-rich surface soils. We therefore attempted to remove organic residues from the MPs using 13\% $\mathrm{KClO}, 50 \% \mathrm{NaOH}, 96 \% \mathrm{H}_{2} \mathrm{SO}_{4}, 65 \% \mathrm{HNO}_{3}$, and $30 \% \mathrm{H}_{2} \mathrm{O}_{2}$. The efficiency with which each reagent removed organic matter was tested by treating 2 g of organic floodplain soil ( $>30 \%$ organic matter; sieved to $1 \mathrm{~mm}$ ) for 1 , 4 , or $7 \mathrm{~d}$ with the reagent at $90{ }^{\circ} \mathrm{C}$ in a sand bath. After digestion, the treated sample was suspended in $27 \% \mathrm{NaCl}$ solution $\left(1.2 \mathrm{~g} \mathrm{~cm}^{-3}\right)$ and centrifuged for $30 \mathrm{~min}$ at $3450 \mathrm{G}$. The supernatant was passed through a $0.45 \mu \mathrm{m}$ filter, and the mass of organic residue was determined gravimetrically. As most organic matter was removed in a short time by $\mathrm{HNO}_{3}$ than by the other reagents (Figure S3), the resistances of PA, PVC, PP, PE, ABS, PC, PS, PET, and PU to $\mathrm{HNO}_{3}$ were tested by treating six particles (250-500 $\mu$ m diameter) of each plastic with $65 \% \mathrm{HNO}_{3}$ at $90^{\circ} \mathrm{C}$ for $4 \mathrm{~d}$.The particles were produced by cutting laboratory vials and bottles of the respective plastic in a knife mill 
and afterwards sieving them to the defined particle size. The effects on the particles were determined by weighing the particles before and after treatment and by analyzing the particles using a FT-IR microscope before and after treatment (Figure S4).

The effectiveness of Raman spectroscopy and FT-IR spectroscopy in characterizing the MP particles was tested. FT-IR spectroscopy was tested in attenuated total reflectance, reflection, and transmission modes. Raman spectroscopy was performed at laser wavelengths of 785 and $633 \mathrm{~nm}$, using 100\% and 5\%-10\% laser power, respectively.

Soil analysis

For texture analysis an aliquot of each soil was dried, passed through a $2 \mathrm{~mm}$ sieve, and heated to 90 ${ }^{\circ} \mathrm{C}$ with $30 \% \mathrm{H}_{2} \mathrm{O}_{2}$ to oxidize all the organic material. Each sample was washed and dispersed in a sodium hexametaphosphate/sodium carbonate solution, and shaken overnight. The particle size distribution was determined using a Mastersizer 2000 laser diffraction system (Malvern Instruments, Malvern, UK). Two subsamples of each soil sample were prepared, and each was analysed three times.

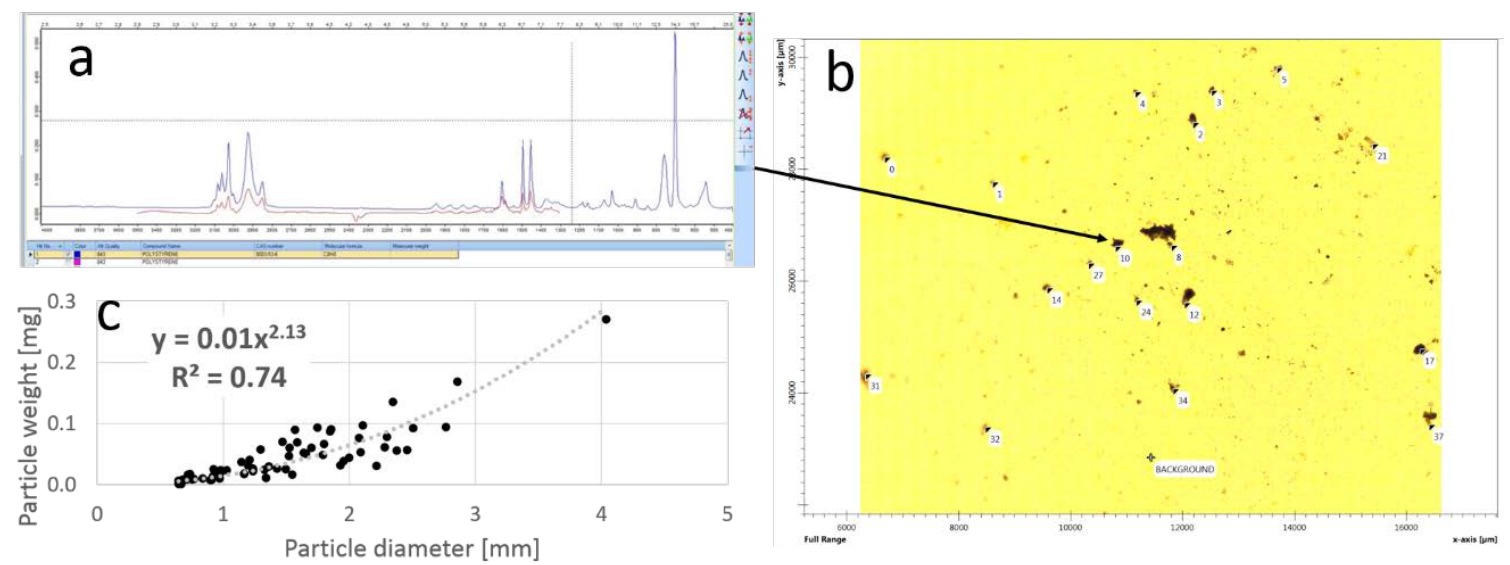

Figure 2. Small microplastic (MP) analysis results. a) Spectra of a MP particle (red) and the polystyrene reference material (blue), b) scan results for a filter paper with small MPs on, and c) relationship between particle weight and particle diameter for MP particles including polypropylene, polyethylene, polyvinyl chloride, polyamide, polycarbonate, and styrene butadiene ( $n=63)$. 
After developing and testing the method for characterising MPs as described above, we applied the following method for the analysis of the floodplain soil samples. A soil sample was dried at $65{ }^{\circ} \mathrm{C}$ in an oven, then passed through a $1 \mathrm{~mm}$ sieve to separate small MPs from large MPs and MEPs. A 50 $\mathrm{mL}$ aliquot of the sieved soil sample was added to $160 \mathrm{~mL}$ of a $27 \% \mathrm{NaCl}$ solution $(\rho=1.2)$. The soil was added as a volume (50 ml) -because of the very different densities of the floodplain soils- and the weight was recorded. The mixture was stirred for $10 \mathrm{~min}$. The solution was then centrifuged at $3450 \mathrm{G}$ for $30 \mathrm{~min}$, and the supernatant was passed through a membrane filter (47 $\mathrm{mm}$ diameter, $0.45 \mu \mathrm{m}$ pore size). The particles were washed from the filter and then treated with $40-80 \mathrm{~mL}$ of $65 \% \mathrm{HNO}_{3}$ at 90 ${ }^{\circ} \mathrm{C}$ for $48 \mathrm{~h}$. Particles stuck to the beaker walls were removed by filling the beaker with $27 \% \mathrm{NaCl}$ ( $\rho=1.2$ ) and leaving the beaker for $24 \mathrm{~h}$. The sample mixture was mixed at $800 \mathrm{rpm}$ for $10 \mathrm{~min}$ for a second time, then centrifuged at $3450 \mathrm{G}$ for $30 \mathrm{~min}$. This second density fractionation was necessary to lower the amount of remaining mineral particles during measurement. The supernatant was passed through an infrared-transparent Whatman Anodisc filter (13 mm diameter, $0.2 \mu \mathrm{m}$ pore size; GE Healthcare Bio-Sciences, Pittsburgh, PA, USA). The filter was then analysed using a Bruker Hyperion 2000 FT-IR spectrometer (Bruker, Billerica, MA, USA). Blank samples indicated that MP contamination could occasionally occur during the sample preparation process because three of the nine blank filters were contaminated. Six particles $<100 \mu \mathrm{m}$ in diameter were found on three of the blank filters. Only particles $>125 \mu \mathrm{m}$ in diameter were therefore mapped to exclude contamination. Each filter was photographed, and all the particles $>125 \mu \mathrm{m}$ in diameter were selected on the screen to schedule them to be automatically analysed (Figure 2). Each particle was scanned 32 times. The measurements were performed in transmission mode between 4000 and $1250 \mathrm{~cm}^{-1}$ because of the infrared impermeability of the filter below $1250 \mathrm{~cm}^{-1}$ (Figure S5). The data were processed using OPUS software (Bruker Corporation 2016). Each spectrum was compared with the entries of a polymer database ${ }^{22}$ using the integrated normalized vector algorithm. Statistical analysis was performed using only the characteristic bands $2980-2780,1800-1740,1760-1670$, and 1480-1400. ${ }^{22}$ The quality criterion for identifying a polymer was a hit quality $>700$. The diameter of each identified particle was measured using the OPUS software. The diameter of each identified particle was measured (Figure 2b), and the MP concentration in each soil sample was calculated from the diameters 
of the particles found using a weight-diameter function (Figure 2c; $r=0.85, p<0.00001$ ). Large MPs and MEPs in the material that did not pass through the $1 \mathrm{~mm}$ sieve were identified by sight and removed, then they were weighed and investigated using the FT-IR instrument described above in attenuated total reflectance mode (32 scans, four times).

Data treatment and statistical analysis

The size of the drainage basin of the river in each floodplain studied was taken from the Swiss Geoportal, ${ }^{27}$ and the sizes of the basins were exported as a .shp file. The area of each drainage basin had an error of about $+/-2 \mathrm{~km}^{2}$. The sizes of the sub-basins were taken from the Swiss hydrological atlas. ${ }^{29}$ The .shp files were processed using the open-source geoinformation system QGIS. The population densities of the drainage basins were available as raster data. ${ }^{30}$ The dataset was based on the 2010 Swiss census and was modified annually. The data we used were for 31 December $2015 .^{30}$ The raster data were summed as polygons over the catchment areas. We could not calculate the numbers of permanent inhabitants of the catchments for study sites 13 and 21 due to insufficient data. The MP recoveries achieved using the different methods were compared using a one-way ANOVA. The homogeneity of the variances was confirmed using a Levene test $(\mathrm{p}=0.96)$. The effect of the $\mathrm{HNO}_{3}$ treatment on the MP recovery was tested by comparing the weights of MPs before and after the treatment using a t-test for dependent samples.

A weight-diameter relationship (Figure 2c) was established based on the size and weight of $63 \mathrm{MP}$ particles extracted from 6 of the studied soils. Thus the relationship was calculated for natural occurring MP including PA, PC, PE, PP, PVC and SBR using a power function, and the Pearson correlation coefficient. The MP and MEP concentrations and the numbers of permanent inhabitants of the catchments did not follow normal distributions, according to the Shapiro-Wilk test $(<0.00000)$ and to visual inspection, so the nonparametric Spearman rank order correlation coefficient $(\rho)$ was used to evaluate the relationships between all datasets. All p values given in the manuscript are for two-tailed tests. The effect of the different distances of the subsample from the River was checked by calculating a nonparametric Kruskal-Wallis test. All statistical analysis were performed using Statistica 7 (StatSoft, Tulsa, OK) software. 


\section{Results and discussion}

Method for extracting, identifying, and quantifying MPs in soil

One reason so few studies of MPs in terrestrial systems have been performed is that the available analytical methods developed for water samples need to be modified to analyse soil samples. One method was recently developed for reliably extracting MPs from soil by accelerated solvent extraction, ${ }^{16}$ but it does not preserve particle size information required for assessing the toxicities ${ }^{3,6}$ and mobilities ${ }^{10}$ of MPs in soil. Another recent method was developed for the analysis of light density plastics like PE and PP from soils. ${ }^{26}$ This method has the big advantage to be simple to use and cost effective because it requires only few chemicals and no FT-IR for the identification of the particles. However, this method is developed for PE and PP exclusively. Various methods are used to identify and quantify plastics in aquatic samples, including optical methods and analytical techniques such as Raman and Fouriertransform infrared (FT-IR) spectroscopy, and pyrolysis gas chromatography mass spectrometry. ${ }^{11} \mathrm{We}$ developed a new method for determining MPs in soil, preserving all the important characteristics of the most common MPs.

For the small MP a number of test were performed to find the best way to do the density separation (to separate MP from mineral particles), to decompose the organic matter and finally analyse the MP. We performed tests using $\mathrm{NaCl}$ and $\mathrm{CaCl}_{2}$ solutions. $\mathrm{NaCl}$ is easily available, and $\mathrm{Na}$ benefits the dispersion of particles, but the maximum solution density that can be achieved using $\mathrm{NaCl}$ is relatively low $(1.2 \mathrm{~g}$ $\mathrm{cm}^{-3}$ ), which may have given low recoveries of PET (density 1.34-1.58 $\mathrm{g} \mathrm{cm}^{-3}$ ) and PVC (density 1.16$1.35 \mathrm{~g} \mathrm{~cm}^{-3}$ ). Van Cauwenberghe et al. ${ }^{3}$ suggested that the optimum solution density is $1.6-1.8 \mathrm{~g} \mathrm{~cm}^{-3}$, which can be achieved using $\mathrm{ZnCl}_{2}$, NaI, or sodium polytungstate. We performed tests using $\mathrm{CaCl}_{2}(1.5$ $\mathrm{g} \mathrm{cm}^{-3}$ )instead because $\mathrm{CaCl}_{2}$ does not harm the environment or humans and is relatively cheap. However, each filter was covered in a thick brownish material after density separation using a $\mathrm{CaCl}_{2}$ solution. We assumed that this brownish material was caused by organic material being extracted from the organic-rich topsoil samples. The organic material would have flocculated because the divalent $\mathrm{Ca}$ ions would have bridged the negative charges of the organic molecules. This process means that $\mathrm{CaCl}_{2}$ and salts of other divalent cations are not suitable for separating MPs from organic-rich soils by density. 
The density separation was done with $27 \% \mathrm{NaCl}\left(1.2 \mathrm{~g} \mathrm{~cm}^{-3}\right)$. Thus, for small MP our method might underestimate the amount of PET and PVC because of the higher densities of these plastics. However, these plastics were only of very limited importance in the large MP fraction of our soils and therefore we do not assume much bias of our results. We tested four different ways of density separation, using a separation cylinder, a self-constructed MP separator, centrifugation and centrifugation with a rubber disc inserted after centrifugation to prevent resuspension of mineral particles. The MP recoveries found using the different methods were between 93-98\% and not significantly different (ANOVA; F=0.36, $\mathrm{p}=0.79$, $\mathrm{n}=12$; Figure S6a). However, samples were processed much more quickly using the centrifuge method than using the other methods, and the rubber disc prevented the mineral particles being resuspended (Figure S6b). We tested different chemicals for the removal of the organic material. Most organic matter was removed in a short time by $\mathrm{HNO}_{3}$ than by the other reagents (Figure S3). The $\mathrm{HNO}_{3}$ treatment caused the ABS, PA, and PET particles to decompose or disintegrate into smaller particles. However, ABS, PA and PET were not found in the large MP fractions (which were not treated with $\mathrm{HNO}_{3}$ ) of our samples, although PA was found in the MEP fractions. So we assumed the $\mathrm{HNO}_{3}$ treatment did not introduce much bias to our results. The demand of ABS, PA, and PET in Europe account for only about $2 \%,<2 \%$, and $7 \%$, respectively, ${ }^{4}$ of the total plastic demand in Europe, and no ABS, PA, or PET particles have previously been found in rivers and lakes in Switzerland. ${ }^{31}$ However, we cannot rule out that smaller amounts of ABS, PA or PET were initially present in the small MP fraction, but destroyed by the acid treatment. The weight and the FT-IR spectra of all the other plastics before and after acid treatment were compared. The weight difference of the particles was always smaller than $2.7 \%$ and not significantly different before and after the treatment. The $\mathrm{HNO}_{3}$ treatment decreased the hit qualities for PC and ABS by $3 \%$ and $6 \%$, respectively, but increased the PS, PU, PET, PVC, and PE hit qualities by 13\%, 7\%, 11\%, 5\%, and 1\% respectively (Figure S4). The decomposition of ABS, PA, and PET could have been avoided by using a 1:1 mixture of $\mathrm{KOH}$ and $\mathrm{NaClO}$, as suggested in an article published after our sample preparation had finished..$^{32}$

For the analysis we tested FT-IR and Raman spectroscopy. FT-IR spectroscopy in transition mode was most suitable for analyzing small MPs on the filters because the spectral quality was better than when reflectance mode was used and because small particles stuck to the crystal in attenuated total reflectance 
mode. Raman spectroscopy caused problems because the MP particles melted because of the high laser energy, and the spectra were of poor quality (Figure S7) compared to the FT-IR spectra (Figure S4).

The results are reported in $\mathrm{mg} \mathrm{kg}^{-1}$ to allow comparisons to be made between the results of studies of MPs in different environmental media. The method allows the most MPs in organic-matter-rich soil to be extracted, identified, and quantified time- and cost-effectively. However, the method has still limitations when it comes to the analysis of ABS, PA, PET and PVC in the small MP range because of its high density or disintegration during the oxidation of organic matter.

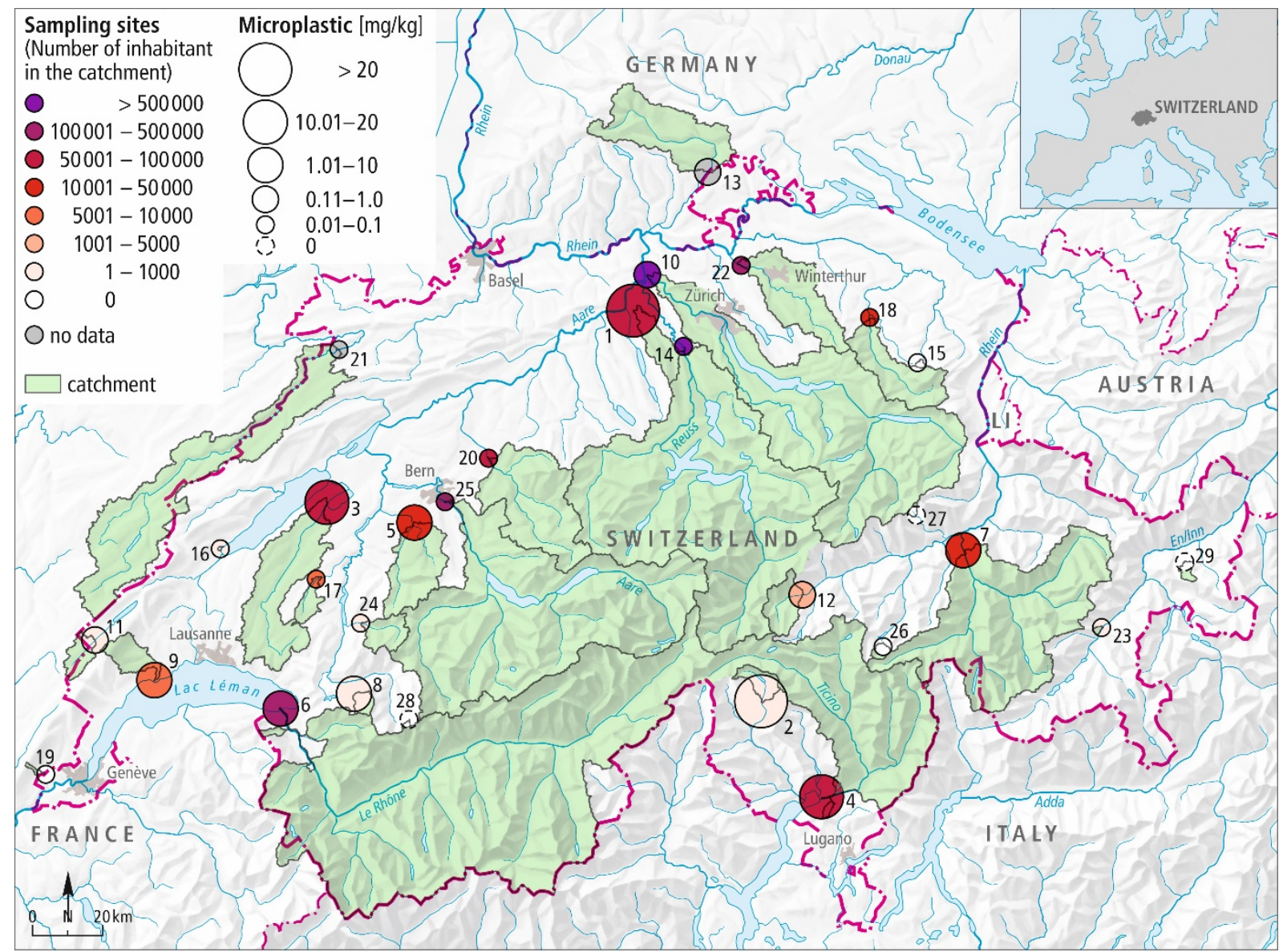

Figure 3 Floodplain sites from which samples were collected showing the associated catchments. Each circle is a sampling point, and the size of the circle corresponds to the microplastic concentration at the sampling site. The colour of the circle corresponds to the number of permanent inhabitants of the relevant catchment area. The number next to each circle refers to the microplastic concentrations found in descending order (i.e., the sampling site with the lowest number had the highest microplastic 
concentration). The individual concentrations of small and large microplastic and mesoplastic can be found in Figure S8.
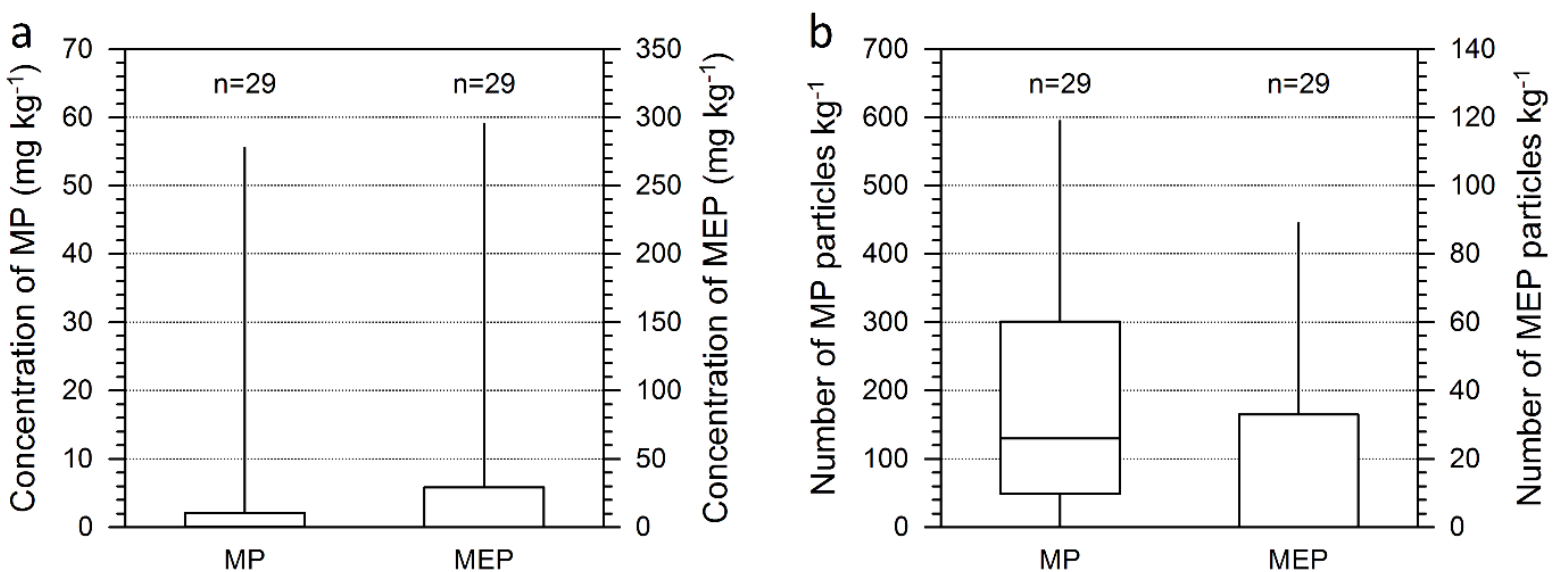

Figure 4 Boxplots of the concentrations of a) microplastic (MP) and mesoplastic (MEP) in $\mathrm{mg} \mathrm{kg}^{-1}$ and b) MP and MEP as number of particles $\mathrm{kg}^{-1}$. More detailed results are presented in Figure S8.

MP and MEP concentrations and compositions

We studied soils from Swiss floodplains at 29 sites across Switzerland (Figure 3). The sites were in a wide range of areas, from remote mountain catchments with no permanent inhabitants at all (Figure S9) to densely populated catchments with up to 1,009,300 permanent inhabitants (Figure S10).

We found MPs at concentrations of up to $55.5 \mathrm{mg} \mathrm{kg}^{-1}$ and up to 593 particles $\mathrm{kg}^{-1}$ in the samples from 26 of the 29 sites (Figure 3, 4). The maximum concentration $\left(\mathrm{mg} \mathrm{kg}^{-1}\right.$ ) was much lower than those found in contaminated soil in Australia (by a factor of 1,200$)^{16}$, in Swiss lake sediment (by a factor of 40), ${ }^{31}$ and in beach sediment (by factors of 20-600). ${ }^{33}$ However, MPs were found even in soils from very remote high mountain areas. All the study sites were in designated nature reserves so should not have been directly affected by MP inputs from waste materials or sewage sludge application. However, flooding might have caused deposition of MP from the river. The mean concentration was relatively low at $5 \mathrm{mg} \mathrm{kg}^{-1}$, and a rough estimate using this concentration indicates that the top $5 \mathrm{~cm}$ of Swiss floodplain soils contain a total of $53.2 \mathrm{t}$ of MPs. MPs can be transported in soil, ${ }^{10,23,24}$ so there may be additional MPs in deeper soil layers. 
In $88 \%$ of the samples, the largest amounts of MPs were in the smallest size range (125-500 $\mu \mathrm{m})$. In general, $85 \%$ of the MPs were small (Figure 5). Small MPs contributed almost 100\% of the total MP concentrations at sites where MEPs were not found, indicating that large MPs formed through the disintegration of larger plastic particles or have the same sources as MEPs. Larger plastic particles such as MEPs were scattered over the floodplains, indicated by the large standard deviations of the MEP and large MP concentrations. The MPs and MEPs in the samples were most commonly PE (contributing 88\% and 35\%, respectively, of the total plastic concentrations, as shown in Figure 6). However, the small and large MPs and MEPs had widely variable compositions. Latex, PVC, and SBR particles were found in the large MP class but not the small MP class, whereas PS particles were found in the small but not the large MP class. Less than half the MEPs were PE, and almost 30\% were PA, but no MPs were PA. Far more MEPs than MPs were natural latex, PS, PVC, and SBR. These compositional differences imply either that small and large MPs and MEPs have different sources or that different plastics resist disintegration and decomposition to different degrees.

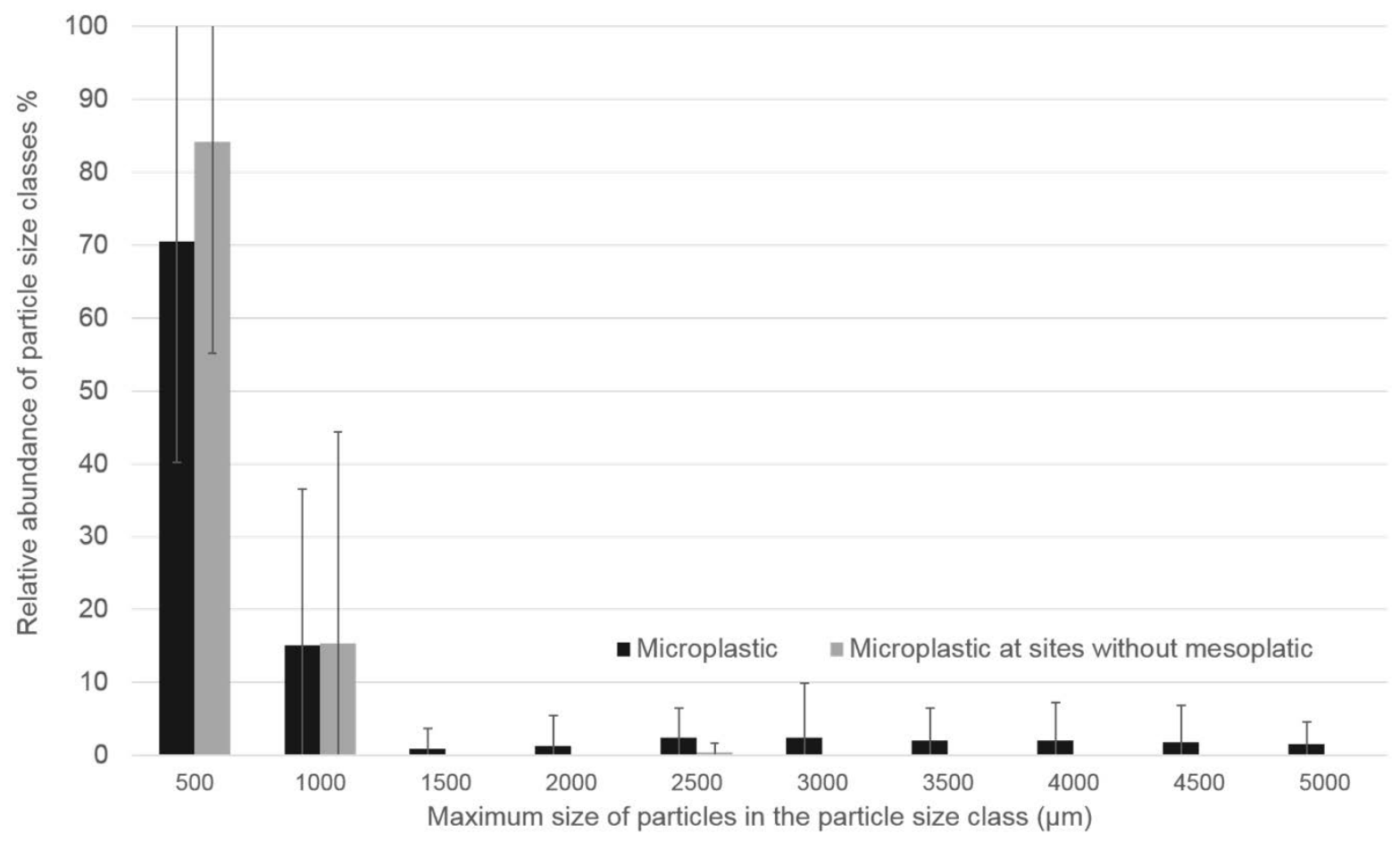

Figure 5 Size distributions of microplastic particles for all the sites and at sites where no mesoplastic particles were found. The error bars show the standard deviations. 


\section{Sources of MPs}

The main sources of MPs relate to human activities, so we selected floodplain soils in river catchments with different numbers of permanent inhabitants $(0-1,009,300)$. The MP concentration and number of permanent inhabitants were correlated $(\rho=0.45, p=0.02, n=27)$, indicating that MP contaminations become more severe as the number of inhabitants increases. This agreed with the results of a study of shoreline sediment performed by Browne et al. ${ }^{34}$ However, no correlation was found between the MEP concentration and the number of permanent inhabitants $(\rho=0.17, p=0.40, n=27)$, probably because of the patchy distribution of plastic waste. Overall, a clear correlation was found between MP and MEP concentrations $(\rho=0.76, p=0.000002, n=29)$, indicating that MPs were formed from MEPs or have partly the same sources. No relationship was found between the MP concentration and soil texture class (e.g., sand $(\rho=-0.08, p=0.68, n=29)$, silt $(\rho=0.15, p=0.44, n=29)$, and clay $(\rho=-0.18, p=0.35, n=29))$, which also agreed with the results for shoreline sediment. ${ }^{34}$ However, the differences in the MP and MEP compositions and 


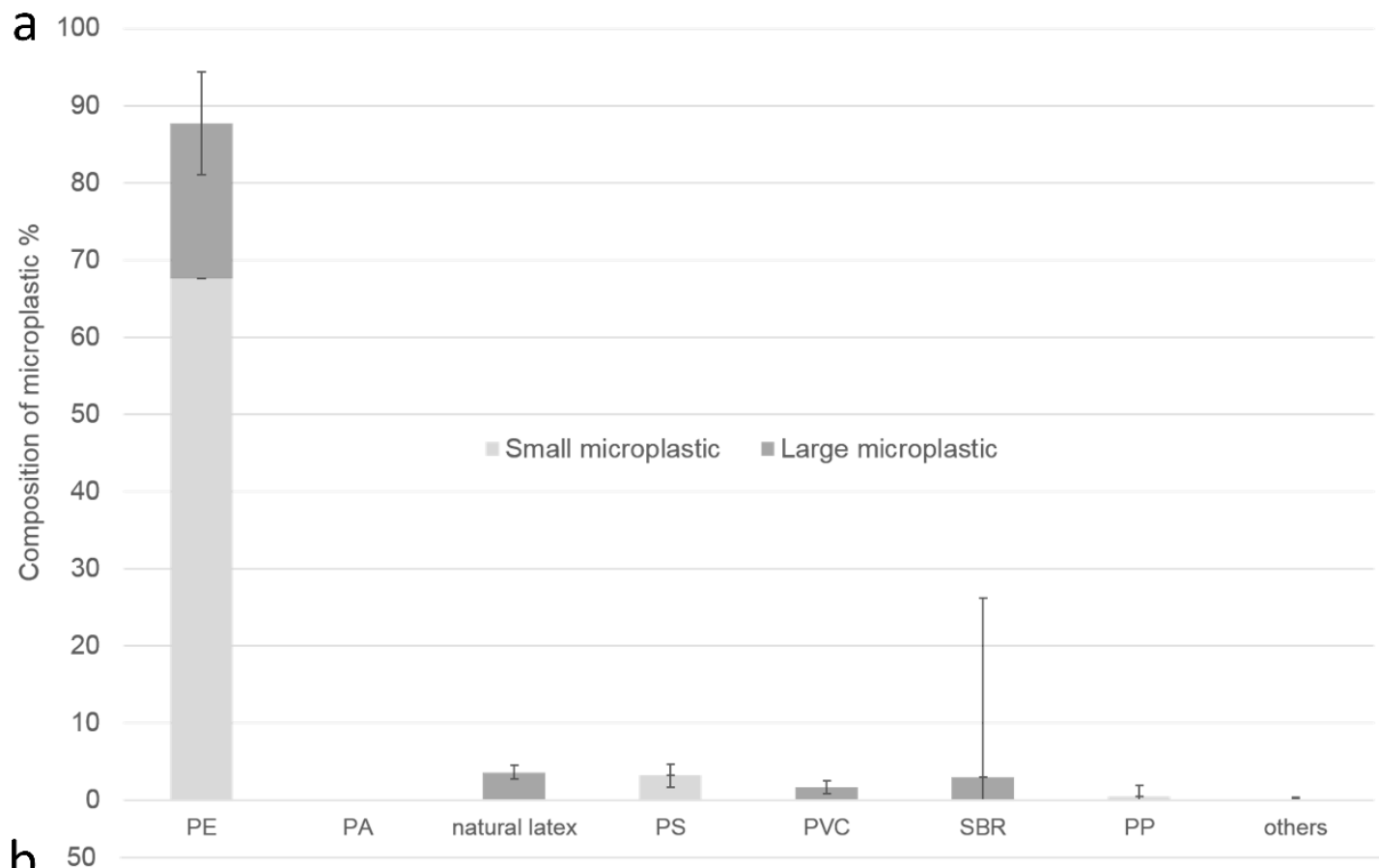

b 50

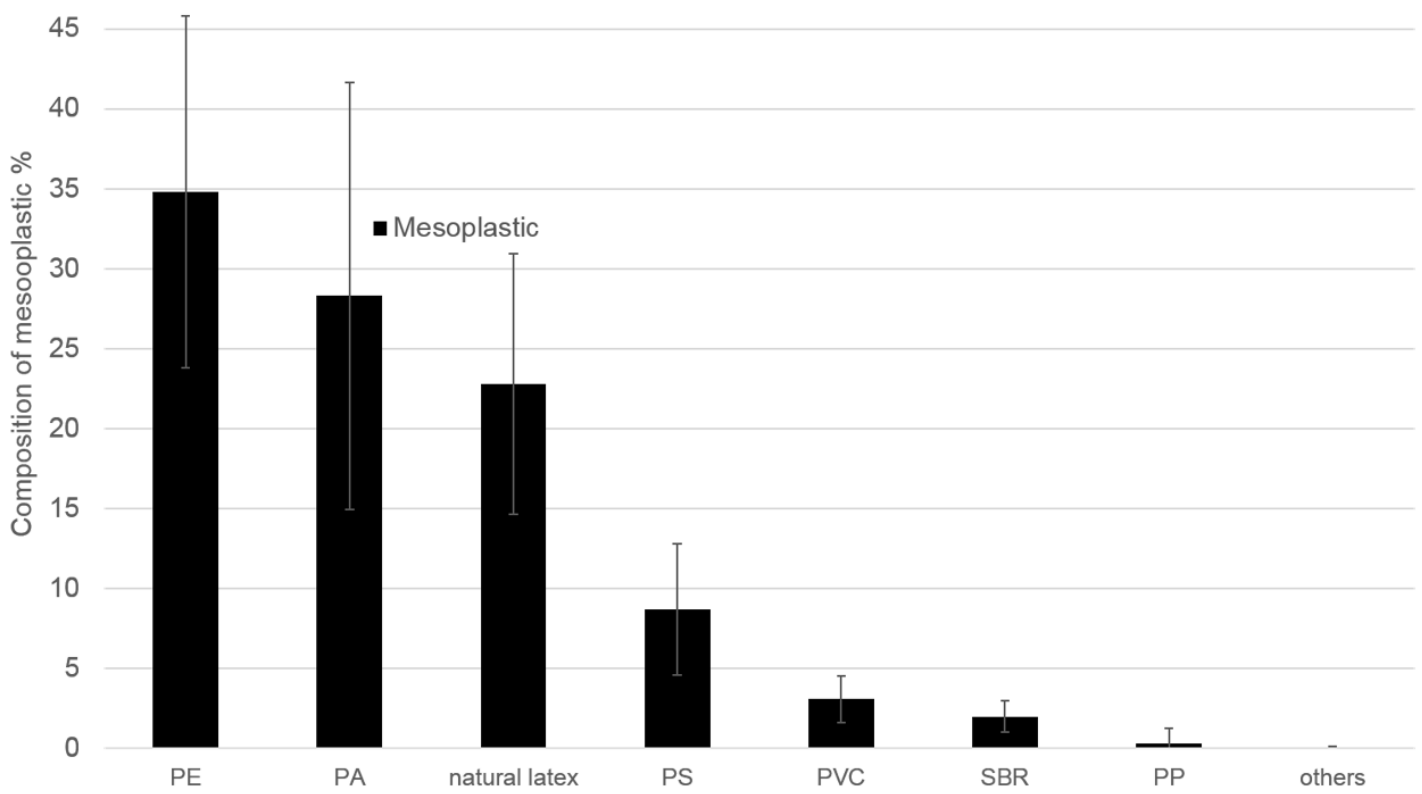

Figure 6 Compositions of (a) small and large microplastics and (b) mesoplastics. The error bars show the standard deviations.

the presence of small particles in the absence of larger particles (Figure 4, 5) indicate that there are also diffuse sources of MPs independent of the disintegration of larger plastic particles. Plastics may be supplied from the diffuse sources in river water or through aeolian transport. The presence of MPs at $90 \%$ of the sites, even at sites in remote high mountain areas without permanent inhabitants and 
unaffected by sewage discharge, suggests that aeolian transport is probably a source of MPs. This conclusion is supported by the small sizes of the particles, which were similar in size to atmospherically deposited particles in Paris, ${ }^{35,36}$ and the clear differences in MP and MEP compositions, which indicate that the MPs and MEPs had different sources (Figure 6).

\section{Implications}

The aim of the study was to facilitate terrestrial MP research and perform the first comprehensive study of MPs in floodplain soils. This is the first time that information on background concentration, size distribution, and composition of MPs in floodplain soils has been published. The MP concentrations were low compared with concentrations in marine environments and polluted soils. ${ }^{16,33}$ However, the presence of MPs in remote high mountains and nature conservation areas indicates that plastics are widely and diffusely distributed and allowed us to identify possible mechanisms through which MPs are transported to and within terrestrial environments. Almost $100 \%$ of the plastic used in in Switzerland is either recycled or incinerated. This is the highest recycling/incineration rate in Europe. ${ }^{4,}{ }^{37}$ There is therefore less potential for MPs to contaminate the Swiss environment than the environments of most other countries.

Future work should focus on the toxicities of MPs to soil organisms, plants, and terrestrial animals and the potential for MPs to be transferred into the human food chain, to allow the importance of MPs in soils to be assessed. Initial studies have shown that MPs are toxic to earthworms. ${ }^{17-19}$ MP concentrations in different soils under different land-use systems around the world should be determined to allow the scale of the MP problem to be assessed. Finally, plastic disintegration and transport mechanisms in soils and MP exchange with the atmosphere and hydrosphere should be investigated to allow the implications of plastic decomposition to be assessed fully.

\section{Supporting information}

Figure S1: Schematic and photo of the microplastic separation device. Figure S2: Photo of the centrifuge vial with rubber disc and close view of the rubber disc. Figure S3: Organic residues found after $24 \mathrm{~h}$ treatments using different reagents. Figure S4: Spectra of $\mathrm{HNO}_{3}$ treated and not treated polyethylene 
and polycarbonate particles. Figure S5: Background spectrum of an Anodisc filter in the range 5400$600 \mathrm{~cm}^{-1}$. Figure S6: Recoveries and mineral residues found using the different separation methods. Figure S7: Raman spectra of the different microplastics at laser wavelengths of $633 \mathrm{~nm}$ and $785 \mathrm{~nm}$. Figure S8: Concentrations of small and large MP and MEP for the individual sites. Figure S9: Photo of three remote high mountain floodplains without permanent inhabitants. Figure S10: Photos of two soils and one study site in populated areas.

\section{Acknowledgements}

We are grateful to Prof. Jörg Hermann and Dr. Peter Tollan (Institute of Geology Bern) for access to the FT-IR Spectrometer, and to the Alfred-Wegener-Institut Helgoland for supplying the polymer database. We thank Dr. Nadim C. Scherrer and Dr. Stefan Zumbühl (Art Technological Laboratory) for access to the Raman spectrometer, Daniela Fischer for help in the lab and we thank Alison Pouliot for improving the quality of the English in the manuscript. This research did not receive any money from funding agencies or companies.

\section{References}

1. UNEP, UNEP frontiers 2016 report: Emerging issues of environmental concern; Nairobi, 2016.

2. Wright, S. L.; Thompson, R. C.; Galloway, T. S., The physical impacts of microplastics on marine organisms: A review. Environ Pollut 2013, 178, 483-492.

3. Van Cauwenberghe, L.; Devriese, L.; Galgani, F.; Robbens, J.; Janssen, C. R., Microplastics in sediments: A review of techniques, occurrence and effects. Mar. Environ. Res. 2015, 111, 5-17.

4. Plastic Europe. Plastics-the facts 2016; PlasticsEurope: 2016.

5. Au, S. Y.; Bruce, T. F.; Bridges, W. C.; Klaine, S. J., Responses of Hyalella azteca to acute and chronic microplastic exposures. Environ. Toxicol. Chem. 2015, 34, (11), 2564-2572.

6. Rehse, S.; Kloas, W.; Zarfl, C., Short-term exposure with high concentrations of pristine microplastic particles leads to immobilisation of Daphnia magna. Chemosphere 2016, 153, 9199.

7. Nobre, C. R.; Santana, M. F. M.; Maluf, A.; Cortez, F. S.; Cesar, A.; Pereira, C. D. S.; Turra, A., Assessment of microplastic toxicity to embryonic development of the sea urchin Lytechinus variegatus (Echinodermata: Echinoidea). Mar. Pollut. Bull. 2015, 92, (1-2), 99-104. 
8. Massos, A.; Turner, A., Cadmium, lead and bromine in beached microplastics. Environ Pollut 2017, 227, 139-145.

9. Rillig, M. C., Microplastic in Terrestrial Ecosystems and the Soil? Environmental Science \& Technology 2012, 46, (12), 6453-6454.

10. Rillig, M. C.; Ziersch, L.; Hempel, S., Microplastic transport in soils by earthworms. Scientific Reports 2017, 7:1362, 1-6.

11. Rocha-Santos, T.; Duarte, A. C., A critical overview of the analytical approaches to the occurrence, the fate and the behavior of microplastics in the environment. Trac-Trends in Analytical Chemistry 2015, 65, 47-53.

12. Nizzetto, L.; Langaas, S.; Futter, M., Do microplastics spill on to farm soils? Nature 2016, 537, (7621), 488-488.

13. Zubris, K. A. V.; Richards, B. K., Synthetic fibers as an indicator of land application of sludge. Environ Pollut 2005, 138, (2), 201-211.

14. Blasing, M.; Amelung, W., Plastics in soil: Analytical methods and possible sources. Sci. Total Environ. 2018, 612, 422-435.

15. Hurley, R., R.; Nizzetto, L., Fate and occurrence of micro(nano)plastics in soils: Knowledge gaps and possible risks. Current Opinion in Environmental Science \& Health 2018, 1, (6-11).

16. Fuller, S.; Gautam, A., A Procedure for Measuring Microplastics using Pressurized Fluid Extraction. Environmental Science \& Technology 2016, 50, (11), 5774-5780.

17. Huerta Lwanga, E.; Gertsen, H.; Gooren, H.; Peters, P.; Salanki, T.; van der Ploeg, M.; Besseling, E.; Koelmans, A. A.; Geissen, V., Microplastics in the Terrestrial Ecosystem: Implications for Lumbricus terrestris (Oligochaeta, Lumbricidae). Environmental Science \& Technology 2016, 50, (5), 2685-2691.

18. Cao, D.; Wang, X.; Luo, X.; G., L.; Zheng, H., Effects of polystyrene microplastics on the fitness of earthworms in an agricultural soil. IOP Conference Series: Earth and Environmental Science 2017, 61, 012148.

19. Rodriguez-Seijo, A.; Lourenco, J.; Rocha-Santos, T. A. P.; da Costa, J.; Duarte, A. C.; Vala, H.; Pereira, R., Histopathological and molecular effects of microplastics in Eisenia andrei Bouche. Environ Pollut 2017, 220, 495-503.

20. Science Communication Unit, Bristol, Science for Environment Policy In-depth Report: Soil Contamination: Impacts on Human Health. In Report produced for the European Commission DG Environment, 2013.

21. Wuana, A.; Okieimen, F. E., HeavyMetals in Contaminated Soils: A Review of Sources, Chemistry, Risks and Best Available Strategies for Remediation. ISRN Ecology 2011, doi:10.5402/2011/402647. 
22. Huerta Lwanga, E.; Vega, J. M.; Quej, V. K.; Chi, J. D.; del Cid, L. S.; Chi, C.; Segura, G. E.; Gertsen, H.; Salanki, T.; van der Ploeg, M.; Koelmans, A. A.; Geissen, V., Field evidence for transfer of plastic debris along a terrestrial food chain. Scientific Reports 2017, 7.

23. Huerta Lwanga, E.; Gertsen, H.; Gooren, H.; Peters, P.; Salanki, T.; van der Ploeg, M.; Besseling, E.; Koelmans, A. A.; Geissen, V., Incorporation of microplastics from litter into burrows of Lumbricus terrestris. Environ Pollut 2017, 220, 523-531.

24. Maass, S.; Daphi, D.; Lehmann, A.; Rillig, M. C., Transport of microplastics by two collembolan species. Environ Pollut 2017, 225, 456-459.

25. Zhang, W.; Morales, V. L.; Cakmak, M. E.; Salvucci, A. E.; Geohring, L. D.; Hay, A. G.; Parlange, J. Y.; Steenhuis, T. S., Colloid Transport and Retention in Unsaturated Porous Media: Effect of Colloid Input Concentration. Environmental Science \& Technology 2010, 44, (13), 4965-4972.

26. Zhang, S.; Yang, X.; Gertsen, H.; Peters, P.; Salánki, T.; Geissen, V., A simple method for the extraction and identification of light density microplastics from soil. Sci. Total Environ. 2018, 616.617, 1056-1065.

27. Bundesamt für Landestopographie. Auengebiete der Schweiz. In Landestopographie, B. f., Ed. 2016.

28. Schwarz, T. Entwicklung, Analyse und Bewertung einer Methodik zur Bestimmung der Mikroplastik - Belastung von Küstensedimenten. University of Bremen, Bremen, 2012.

29. HADES, Hydrologischer Atlas der Schweiz. Universität Bern and Bundesamt für Umwelt: 2016.

30. Statistik, B. f., Bevölkerungsdichte. In Statistik, B. f., Ed. 2015.

31. Faure, F.; Alencastro, F. Evaluation de la pollution par les plastiques dans les eaux de surface en Suisse; École Polytechnique Fédérale de Lausanne: Lausanne, 2014.

32. Enders, K.; Lenz, R.; Beer, S.; Stedmon, C. A., Extraction of microplastic from biota: recommended acidic digestion destroys common plastic polymers. ICES J. Mar. Sci. 2017, 74, (1), 326-331.

33. Carson, H. S.; Colbert, S. L.; Kaylor, M. J.; McDermid, K. J., Small plastic debris changes water movement and heat transfer through beach sediments. Mar. Pollut. Bull. 2011, 62, (8), 17081713.

34. Browne, M. A.; Crump, P.; Niven, S. J.; Teuten, E.; Tonkin, A.; Galloway, T.; Thompson, R., Accumulation of Microplastic on Shorelines Woldwide: Sources and Sinks. Environmental Science \& Technology 2011, 45, (21), 9175-9179.

35. Dris, R.; Gasperi, J.; Mirande, C.; Mandin, C.; Guerrouache, M.; Langlois, V.; Tassin, B., A first overview of textile fibers, including microplastics, in indoor and outdoor environments. Environ Pollut 2017, 221, 453-458. 
36. Dris, R.; Gasperi, J.; Saad, M.; Mirande, C.; Tassin, B., Synthetic fibers in atmospheric fallout: A source of microplastics in the environment? Mar. Pollut. Bull. 2016, 104, (1-2), 290-293.

37. Science for Environmental Policy. Plastic Waste: Ecological and Human Health Impacts; European Commission: 2011. 